\title{
Correction to: A hybrid approach to energy efficient clustering and routing in wireless sensor networks
}

\author{
Ushus Elizebeth Zachariah $^{1} \cdot$ Lakshmanan Kuppusamy $^{1}$
}

Published online: 15 February 2022

๑) Springer-Verlag GmbH Germany, part of Springer Nature 2022

\section{Correction to Evolutionary Intelligence https://doi.org/10.1007/s12065-020-00535-0}

Unfortunately, the author "Lakshmanan Kuppusamy" was missed to include as corresponding author. Now, correct author group with corresponding authorship is given below.

Ushus Elizebeth Zachariah ${ }^{1}$. Lakshmanan Kuppusamy $^{1}$.

Publisher's Note Springer Nature remains neutral with regard to jurisdictional claims in published maps and institutional affiliations.

The original article can be found online at https://doi.org/10.1007/ s12065-020-00535-0.

Ushus Elizebeth Zachariah ushus@vit.ac.in

$\triangle$ Lakshmanan Kuppusamy

klakshma@vit.ac.in

1 School of Computer Science and Engineering, Vellore Institute of Technology, Vellore 632014, India 